Cornell Law Library

Scholarship@Cornell Law: A Digital Repository

Cornell Law Faculty Publications

Faculty Scholarship

$3-1-1985$

\title{
The Effects of Sex-Role Attitudes and Group Composition on Men and Women in Groups
}

Valerie P. Hans

Cornell Law School, valerie.hans@cornell.edu

Nancy Eisenberg

Follow this and additional works at: http://scholarship.law.cornell.edu/facpub

Part of the Behavior and Behavior Mechanisms Commons, Gender and Sexuality Commons, and the Social Psychology and Interaction Commons

\section{Recommended Citation}

Hans, Valerie P. and Eisenberg, Nancy, "The Effects of Sex-Role Attitudes and Group Composition on Men and Women in Groups" (1985). Cornell Law Faculty Publications. Paper 331.

http://scholarship.law.cornell.edu/facpub/331

This Article is brought to you for free and open access by the Faculty Scholarship at Scholarship@Cornell Law: A Digital Repository. It has been accepted for inclusion in Cornell Law Faculty Publications by an authorized administrator of Scholarship@Cornell Law: A Digital Repository. For more information, please contact jmp8@cornell.edu. 


\title{
The Effects of Sex-Role Attitudes and Group Composition on Men and Women in Groups
}

\author{
Valerie P. Hans ${ }^{1}$ \\ Division of Criminal Justice and Department of Psychology, University of Delaware
}

\author{
Nancy Eisenberg \\ Arizona State University
}

The dual impact of group gender composition and sex-role attitudes on selfperceptions and social behavior was explored. Androgynous and stereotyped men and women were placed in groups of skewed sex composition. Subjects' self-descriptions of masculine attributes shifted significantly in the group environment. In some instances, sex role-stereotyped subjects responded most stereotypically when their gender was in the minority in the group. Differences between men and women and between androgynous and stereotyped subjects in sex role-related preferences for group roles and discussion topics were also found.

In the past decade or so, researchers frequently have examined the development and functioning of sex-role stereotypes and the manner in which these stereotypes affect individuals' social behavior (Bem, 1974, 1975; Spence \& Helmreich, 1978; Spence et al., 1974). In addition, there is a small but growing body of experimental work concerning the ways in which our awareness of gender is enhanced by situational features of social life. For example, in a number of studies, researchers have established that consciousness of gender will be heightened in instances in which one's own gender is in the minority in a group. McGuire and Padawer-Singer (1976) proposed that people concentrate on the distinctive aspects of the relation-

${ }^{1}$ To whom correspondence should be addressed at Division of Criminal Justice, University of Delaware, Newark, Delaware 19716. 
ship between the self and the social context. In support of this proposition, they found that sixth graders who were asked to tell about themselves were more likely to mention their gender spontaneously when their gender was in the minority rather than the majority in their classrooms. Observers of group interaction also attend differentially to individuals who are in the minority as opposed to the majority in a group. For instance, Taylor et al. (1978) varied the sex composition of groups and found that observers were more likely to remember those of the minority gender and to perceive them as playing a sex-stereotyped role in the group. Similarly, Kanter (1977a, b) documented the high visibility of token individuals in business settings and the concomitant stereotypic distortions and misperceptions of these individuals' characteristics. Furthermore, in an experimental study, Heilman (1980) varied the sex composition of an applicant pool. He found that women applicants were perceived more stereotypically and evaluated less favorably by MBA students for a managerial job when women constituted only a small proportion of the applicant pool.

One important question about the sex composition of groups that has not been explored in any depth is how the heightened salience of gender will affect the behavior (especially the sex role-related behavior) of an individual who finds himself or herself in the minority in a group. One possible outcome, derived from conformity theory and research (Asch, 1956), is that those who are in the minority gender will simply conform to those in the majority gender in their sex role-related behavior. A second possibility is that shifts in sex-role behavior will be asymmetrical. Greater value is often placed on male characteristics and male preferences (Andersen, 1983), and women sometimes exhibit greater conformity than men in group settings (Eagly, 1978). As a result, when men are in the majority, women in the minority may conform, but when the situation is reversed, men in the minority gender may not conform. A third hypothesis is suggested by the research on objective self-awareness that shows that individuals in a heightened state of awareness alter their behavior in the direction of their "ideal" selves. It follows that when consciousness of gender is heightened by being in the minority gender in a group, people should alter their sex role-related behavior in a direction consistent with their sex-role attitudes. Thus, men and women with traditional sex-role attitudes should be especially likely to behave stereotypically when they find themselves in the minority gender in a group. In contrast, men and women|who characterize themselves as androgynous would not be expected to show the same pattern. No unequivocal prediction for androgynous people can be derived directly from objective self-awareness theory. However, compared to stereotyped individuals, androgynous people in the minority should be better able to respond to situational demands and thus might be likelier to exhibit the behaviors and preferences of the majority. 
While there is relatively little research on this topic, some suggestive findings are provided by two experiments on group sex composition. Ruble and Higgins (1976) reported that sex composition affected the degree to which male versus female stereotypes were included in subjects' self-descriptions. In their experiment, college students in the minority (a single male or female in an otherwise opposite-sex group) were more likely to describe themselves with traits typically associated with the opposite sex than were subjects in groups with other sex compositions. In general, these college students tended to describe themselves in an androgynous manner. In a second study reported by Ruble and Higgins, fifth graders (a more stereotyped subject sample than the college students) also were placed in groups of varying sex composition. Fifth-grade girls described themselves in the most masculine terms and were the least sex typed when they were in the minority in a group. However, the results for fifth-grade boys were mixed. Overall, the existing research is consistent with the conclusion that, when one is in the minority, there may be movement in the majority direction in self-descriptions and sex role-related behavior, at least for females.

The research described in this paper was designed to explore more directly whether the gender composition of a group affects the selfperceptions and sex role-related preferences of individuals in a group. According to the hypothesis derived from objective self-awareness theory, an individual's own sex-role attitudes should interact with the gender composition of the group. Stereotyped individuals should behave most stereotypically when in the minority, whereas androgynous people should not show this pattern. Another possible outcome is that people in the minority gender will simply conform to the majority gender regardless of gender or sex-role attitudes. Finally, shifts in sex-role preferences and behavior may be asymmetrical. While women in the minority may conform to men in the majority, minority men may be reluctant to conform to majority women.

We examined these hypotheses in the current study by varying the gender composition of groups. In approximately half the groups a|woman was in the minority (one woman and three men), while in the other half a man was in the minority (one man and three women). To explore the interaction between sex-role attitudes and group sex composition, about half the groups with each sex configuration were composed of members who had been classified previously as androgynous, while the other half consisted of sex-stereotyped individuals. Subjects in the groups provided self-descriptions, indicated their preferences for a number of sex role-related behaviors, and engaged in group discussion.

In addition, the influence of both gender and sex-role attitudes on social behavior and preferences was explored. Other researchers have documented differences between men and women in group behaviors (e.g., 
Piliavin \& Martin, 1978). It is commonly assumed that, regardless of group composition, men and women with varying sex-role attitudes behave differently in social settings, and this assumption has been confirmed for some behaviors (Bem, 1975). Yet some researchers such as Orlofsky (1981) have failed to find expected relations between sex-role attitudes and sex role-related preferences. In the present study, differences between androgynous and stereotyped individuals' preferences and behavior in a small group context were examined.

\section{METHOD}

\section{Subjects}

Subjects were 34 female and 38 male introductory psychology students who participated in the study for course credit. Subjects filled out the Personal Attributes Questionnaire (PAQ; Spence et al., 1974) along with other unrelated forms during the first week of class. Eighteen women and 22 men had been classified as androgynous on the basis of the test, while 16 women and 16 men were categorized as sex role stereotyped (masculine for males; feminine for females). The method for classification was that used by Spence and Helmreich (1978).

\section{Procedure}

Groups consisted of one man and three women or one woman and three men, depending on the experimental condition. The men and women in the same group were either all androgynous or all sex stereotyped. The order in which groups of varying sex compositions and of different sex-role orientations were run in the experiment was randomly determined.

The actual experiment began 8 weeks after subjects had completed the PAQ during the first week of class. Each group of four was escorted to a private room and seated. The experimenter (one of two females) told the group members that the researchers were interested in how groups of people organize themselves for a group performance task. She informed them that they would be participating in a group discussion with one another. She stated that before they began the discussion, they would be filling out some forms. The experimenter then distributed copies of the PAQ, which group members filled out individually but in one another's presence.

After they had completed the PAQ, subjects were told that there were a number of decisions to be made by the experimenter about how to proceed 
with the group discussion and that their input was desired and would be used in making these decisions.

Subjects were given a Group Role Form, which explained the roles they could play in the upcoming group discussion.

You could be the group discussion leader, in which case you would have the responsibility of leading the discussion. Alternatively, you could be the group secretary, whose responsibility would be to write down important points made in the discussion. Finally, you could be a regular group member, with no special responsibility outside of participating in the discussion.

Subjects were asked to indicate on seven-point scales $(1=$ strongly opposed to doing it; 7 = very much would like to do it) how much they would like to perform each of these three roles. They were also asked to indicate which role was their first choice. Finally, they were asked, "If others in the group also want your first choice, how willing would you be to switch from your first choice?" They responded to this final question on a scale which ranged from 1 (not at all willing) to 7 (extremely willing). According to pretesting, male college students, in comparison to female students, preferred the role of group leader $[t(79)=2.84, p<.006]$, whereas females preferred the role of secretary $[t(79)=-10.90, p<.001]$. Neither gender preferred the role of regular group member $[t(79)=-.91, \mathrm{~ns}]$.

Next, subjects were given a form entitled Topic Choice and were asked to indicate on a five-point scale their interest in talking about the following topics in the upcoming discussion: (1) disciplining children, (2) resolving an argument between an employer and an employee in a business, (3) consoling someone whose mother or father had died recently, and (4) buying a car. Pretesting with college students had demonstrated that 1 and 3 were considered feminine activities $[t(76)=-5.75$ and $-9.56, p$ 's $<$ $.001]$, while 2 and 4 were viewed as masculine topics $[t(76)=3.79$ and 9.42 , $p$ 's $<.001$ ]. Subjects were also asked to provide their first choice for a discussion topic and to indicate their willingness (on a seven-point scale) to switch topics to accommodate other group members' preferences.

After completing these three forms, subjects were told that while the experimenter was compiling the responses, she wanted to solicit their help with another issue. They were told that there were plans to restructure the format of the introductory psychology class and that the faculty were interested in obtaining students' opinions on how best to design the course. Subjects then engaged in short (10-min) discussions on whether to organize the introductory psychology course as all lecture, lecture plus small groups, small groups only, or individual study. The discussions continued until a decision was reached and were tape recorded for later analysis. At the conclusion of the discussion, each subject rank ordered the other three group members in terms of how much leadership each had provided in the 
discussion and in terms of how much information or how many ideas they contributed to the group. This ended the experiment; all subjects were debriefed.

\section{RESULTS}

\section{Manipulation Check}

Both subjects' Masculinity and subjects' Femininity scores on the PAQ that they filled out during the first week of classes were submitted to a 2 (Sex of subject) $\times 2$ (Group members' sex typing) $\times 2$ (Majority-minority status) analysis of variance. There were significant main effects for Sex of subject and Group members' sex typing and a significant interaction between these variables in the expected direction for both sets of scores, confirming that the attempt to compose groups of stereotyped or androgynous subjects was successful. The interaction between Sex of subject and Group members' sex typing on Femininity scores $[F(1,64)=$ $13.50, p<.001]$ was due to the fact that androgynous men had higher Femininity scores than stereotyped men $[F(1,64)=31.14, p<.001]$, while androgynous and stereotyped women's scores did not differ significantly $[F(1,64)=2.26, p<.14]$. Similarly, the significant interaction between Sex of subject and Group members' sex typing for Masculinity scores $[F(1,64)$ $=37.88, p<.001]$ indicated that androgynous and stereotyped women's scores differed in the predicted direction $[F(1,64)=68.18, p<.001]$, while their male counterparts' scores did not differ significantly $[F(1,64)=1.86$, $p<.18]$.

\section{Femininity and Masculinity Change Scores}

To examine the hypothesis that one's self-concept or self-description may change as a joint function of both sex-role stereotyping and minority or majority status within a group, subjects' scores on the PAQ completed in the group were subtracted from their scores obtained during the first week of school. Two change scores were computed for each subject: one for the Femininity scale and one for the Masculinity scale. According to two 2 (Sex of subject) $\times 2$ (Group members' sex typing) $\times 2$ (Majority-minority status) analyses, there were no significant effects on the Femininity change scores, but the Masculinity change scores were affected by the variables. First there was a significant effect for Sex of subject $[F(1,64)=8.26, p<.006]$. 
Women evidenced only a slight shift toward greater masculinity $(M=.15)$, while men shifted their responses in a less masculine direction $(M=-1.53)$. The Sex of subject $X$ Group members' sex typing interaction was marginally significant $[F(1,64)=3.63, p<.06]$. Stereotyped females shifted to more masculine self-descriptions $(M=1.13$ ), while androgynous females (like androgynous and stereotyped males) shifted in a less masculine direction ( $M$ $=-.72)$. These means were significantly different $[F(1,64)=4.22, p<$ .04].

\section{Role Choices}

Four $2 \times 2 \times 2$ analyses of variance were computed to examine the effects of Sex of subject, Group members' sex typing, and Majorityminority status on role preferences. For the leader role, there was an effect for Group members' sex typing $[F(1,64)=3.73, p<.058]$. Androgynous group members $(M=4.85)$ were more likely than stereotyped group members $(M=4.14)$ to prefer the leadership role.

Subjects' preference scores for the secretarial role are displayed in Table I. There was a significant effect for Sex of subject $[F(1,64)=41.99, p$ $<.001$ ], with women $(M=4.47)$ being much more willing than men $(M=$ $2.39)$ to serve as secretary for the group. There were also two significant interactions: Group members' sex typing $X$ Majority-minority status $[F(1$, $64)=4.56, p<.04]$ and Group members' sex typing $X$ Sex of subject $[F(1$, $64)=6.00, p<.02]$. Both these interactions were due primarily to the minority-status stereotyped females' much greater willingness to serve (indeed, insistence on serving!) in the secretarial role. According to tests of simple effects, androgynous and sex-stereotyped individuals with minority status differed significantly $[F(1,64)=4.18, p<.05]$, as did androgynous and stereotyped females' responses $[F(1,64)=4.49, p<.04]$. As indicated in Table I, males generally were unwilling to serve as secretary.

Subjects' preferences for leadership and secretarial roles were analyzed in a second way. Each subject's score for the secretary role was subtracted from his or her leadership score, yielding a difference. The higher the difference score, the more masculine role choices of the subject. These scores are presented in Table II. Main effects for both Sex of subject $[F(1,64)=$ $36.67, p<.001]$ and Group members' sex typing $[F(1,64)=4.49, p<.04]$ were significant, as was the interaction between these two variables $[F(1,64)$ $=6.95, p<.01]$. As might be expected, men and androgynous group members made more masculine role choices. The differential preferences of men and women were most pronounced in sex-stereotyped compared to androgynous groups. Tests of simple effects showed that androgynous 
Table I. Preference for Secretary Role ${ }^{a, b}$

\begin{tabular}{lll}
\hline \multicolumn{1}{c}{ Group } & Majority status & Minority status \\
\hline Androgynous & & \\
$\quad$ Females & $4.17(N=12)$ & $3.50(N=6)$ \\
$\quad$ Males & $2.72(N=18)$ & $2.00(N=4)$ \\
Stereotyped & & \\
Females & $4.67(N=12)$ & $6.25(N=4)$ \\
Males & $2.08(N=12)$ & $2.25(N=4)$ \\
\hline
\end{tabular}

${ }^{a}$ The higher the number, the greater the preference for the secretary role.

${ }^{b}$ Sex of subject main effect: $F(1,64)=41.99, p<.001$. Group members' sex typing $\times$ Majority-minority status interaction effect: $F(1,64)=4.56, p<.04$. Sex of subject $\times$ Group members' sex typing interaction effect: $F(1,64)$ $=6.00, p<.02$.

females had significantly higher scores than stereotyped females $[F(1,64)=$ $9.84, p<.003]$.

Subjects' preferences for being a regular group member are presented in Table III. The triple interaction was statistically significant $[F(1,64)=$ $4.52, p<.04]$. Although none of the comparisons among means reached statistical significance, the interaction effect appeared to be due to the greater willingness of stereotyped women with majority status and stereotyped men with minority status to prefer the role of ordinary group member ( $M=5.50$ for both groups). In contrast, stereotyped men in the majority and androgynous men in the minority were less likely to express a preference for the group-member role ( $M=4.25$ for both groups).

Table II. Preference for Leadership Role Minus Preference for Secretary Role ${ }^{a, b}$

\begin{tabular}{lrr}
\hline \multicolumn{1}{c}{ Group } & Majority status & Minority status \\
\hline Androgynous & & \\
Females & $.58(N=12)$ & $1.17(N=6)$ \\
Males & $2.11(N=18)$ & $3.50(N=4)$ \\
Stereotyped & & \\
Females & $-1.33(N=12)$ & $-1.75(N=4)$ \\
Males & $2.83(N=12)$ & $1.75(N=4)$ \\
\hline
\end{tabular}

${ }^{a}$ The higher the number, the more masculine the choices. ${ }^{b}$ Sex of subject main effect: $F(1,64)=36.67, p<.001$. Group members' sex typing main effect: $F(1,64)=4.49$, $p<.04$. Sex of subject $\times$ Group members' sex typing interaction effect: $F(1,64)=6.95, p<.01$. 
Table III. Preference for Group-Member Role ${ }^{a, b}$

\begin{tabular}{lll}
\hline \multicolumn{1}{c}{ Group } & Majority status & Minority status \\
\hline Androgynous & & \\
$\quad$ Females & $5.25(N=12)$ & $5.17(N=6)$ \\
$\quad$ Males & $5.06(N=18)$ & $4.25(N=4)$ \\
Stereotyped & & \\
$\quad$ Females & $5.50(N=12)$ & $4.75(N=4)$ \\
Males & $4.25(N=12)$ & $5.50(N=4)$ \\
\hline
\end{tabular}

${ }^{a}$ The higher the number, the greater the preference for being a group member.

${ }^{b}$ Sex of subject $\times$ Group members' sex typing $\times$ Majorityminority interaction effect: $F(1,64)=4.52, p<.04$.

\section{Willingness to Change Role}

Subjects' willingness to change their first choice of role in the event that others in the group also wanted that same role was affected by Sex of subject and Group members' sex typing. Women $(M=5.76)$ were more willing than men $(M=5.16)$ to switch roles $[F(1,64)=4.12, p<.05]$. Androgynous group members $(M=5.70)$ were also more willing than stereotyped members $(M=5.13)$ to change $[F(1,64)=4.07, p<.05]$.

\section{Topic Choice}

To examine topic-choice preferences, the ratings for the two feminine topics were subtracted from the combined ratings for the two masculine topics. A higher score thus indicated a preference for more masculine topics. Not surprisingly, men $(M=.76)$ preferred more masculine discussion topics than women $(M=-1.00)[F(1,64)=15.37, p<.001]$. Group members with minority status $(M=.78)$ also preferred more masculine topics than group members in the majority $(M=-.35)[F(1,64)$ $=6.56, p<.01]$. Subjects' willingness to change their first choice of discussion topic was unaffected by the experimental variables.

\section{Group Discussion}

To analyze the group discussions, the number of times members of each sex spoke and the length of each discussion were timed. The number of instances the minority member in a group spoke was divided by the number of seconds in the discussion to yield a frequency per second figure. The 
number of times majority members spoke was divided first by three (the number of majority members in a group) and then by the number of seconds in the discussion to yield a mean frequency per second figure. Interrater reliability for these frequencies was .82 . There were no significant differences on the frequency measures for any of the independent variables.

\section{Leadership and Information Ratings by Group Members}

According to the analysis of subjects' rankings of other group members' leadership, there was a significant Group members' sex typing $X$ Majority-minority status interaction $[F(1,62)=4.44, p<.04]$. Androgynous subjects in the minority $(M=1.45)$ were more likely to be viewed as leader than stereotyped subjects in the minority $(M=2.14)[F(1$, $62)=4.50, p<.04]$. No other comparisons among means were statistically significant.

Subjects' ranking of how much information or ideas other group members had contributed to the group were unaffected by the experimental variables.

\section{DISCUSSION}

In the present study, individuals' sex role-related self-descriptions and behavioral preferences were affected by participation in a group discussion situation in several ways. Placing persons in mixed-sex discussion groups caused shifts in their self-descriptions along masculine dimensions. The anticipation of group discussion appeared to have a moderating influence on the self-report of masculine attributes, in that persons who had initially described themselves as high on masculine characteristics (androgynous males and females as well as stereotyped males) shifted downward in a less masculine direction, whereas stereotyped females shifted upward. This pattern bears some resemblance to the opposite-sex convergence in the self-descriptions of subjects in mixed-sex groups reported by Ruble and Higgins (1976). Similarly, Hammen and Peplau (1978) found that female subjects who waited for an experiment with another woman reported more liberal sex-role attitudes (the direction characteristic of women) than women who waited for the experiment with a man.

The fact that subjects shifted their self-descriptions of masculine but not feminine attributes is intriguing. It could be argued that the asymmetry in change of self-descriptions is due to the differential value ascribed to male and female characteristics. However, a more compelling explanation 
may lie in the overlap between the instrumental nature of the group task and the instrumental character of the masculine attributes of the PAQ. Helmreich et al. (1981), in a factor analytic study of the PAQ, found that PAQ items could be characterized by the two dimensions of femininity/ expressivity and masculinity/instrumentality. Group decision making is primarily an instrumental task; thus, anticipation of participation in the group might have heightened the awareness of masculine/instrumental characteristics rather than feminine/expressive ones. It may be that the salience of sex-role attributes is a function not only of the distinctiveness of one's gender in a social group (Kanter, 1977a,b; McGuire \& Padawer-Singer, 1976; Taylor et al., 1978) but also of the gender dimensions of the group task. A similar proposal has been advanced by Kimble et al. (1981), who compared men and women's assertiveness in groups of varying sex compositions. They found that both the gender composition of the group and the structure of the group discussion affected conversational dominance. Kimble et al. argued that the instrumentality and expressiveness of a situation may determine which gender is dominant in conversation. The fact that situational characteristics in this study impinged even on self-descriptions raises some fascinating questions about the psychological preparation and shifts individuals undergo prior to engaging in group interactions.

The hypothesis that being in the minority would heighten the stereotypical responding of sex role-stereotyped individuals received some modest support in that stereotyped women in the minority expressed the greatest preference for the secretarial role. However, stereotyped men in the minority did not, as was expected, evince much interest in adopting a leadership position. Indeed, the average leadership preference score was somewhat lower for stereotyped males in the minority $(M=4.00)$ than the mean for other males $(M=4.93)$. Instead, stereotyped men in the minority preferred to be ordinary group members, perhaps because they were uncomfortable with the thought of leading a group of women. While this is commonplace in business settings, it may well lie outside the experiences of stereotyped college men. Contrary to the results of McGuire and Padawer-Singer (1976), in this study majority or minority status was not associated with differential shifts in self-descriptions. Rather, the skewed sex composition of the group triggered changes for both minorities and majorities. On the whole, the status variable had only a weak impact in the present study. There was a significant main effect for status in just 1 of the 12 ANOVAs conducted, and status was a variable in three significant interactions. In this study, there was no evidence of greater overall conformity on the part of the minority or of asymmetrical shifts by men and women in the minority. 
In light of the relative absence of majority-minority status effects in this experiment, it is interesting to note the results of a recent study of sex ratios and sexual harassment on the job. Gutek and Morasch (1982) found that women in both male-dominated and female-dominated jobs were more likely to report that sexual harassment was a major problem at work than women whose job environments were more balanced. Gutek and Morasch concluded that male and female sex roles were downplayed in more integrated work settings and emphasized in work settings with skewed sex ratios. Thus, the fact of skewness, rather than the status as a majority or a minority member, created salience for sex roles and sex role-related behavior on the job. The same phenomenon may have occurred in the present study.

In recent work on the concept of androgyny, researchers have debated the relation between androgyny and adaptability. Bem and others (Bem, 1975; Bem \& Lenney, 1976; Bem et al., 1976; Burchardt \& Serbin, 1982; Harrington \& Andersen, 1981) have found that androgynous individuals exhibit superior personality adjustment, greater adaptability, and more behavioral flexibility, although other researchers have argued that the presence of masculine traits rather than androgyny is associated with greater flexibility or psychological health (Jones et al., 1978; Taylor \& Hall, 1982). Some of the findings in the present study point to the success and flexibility of our androgynous subjects. Androgynous subjects (along with women) were more willing to change roles to accommodate other group members' preferences. They also expressed a preference for the leadership role, and, in fact, androgynous subjects in the minority were more likely than stereotyped subjects in the minority to be viewed by their peers as the discussion leader. Finally, stereotyped women in the minority were insistent upon the secretarial role, while androgynous women in the minority were more willing to take on other roles. In stereotyped groups in which males were in the minority, divergent behavioral preferences may have caused problems. Males wanted to be ordinary group members, females wanted to be secretaries, no one desired the leader role, and stereotyped subjects were less willing than androgynous subjects to switch roles to satisfy others. Whether the combination of these behavior preferences caused actual group dysfunction cannot be answered by our data, but it is an important question for future research. Overall, the stereotyped versus androgynous character of the group proved to be a relatively powerful variable. Of 12 ANOVAs, there were three significant main effects and six significant interactions involving group sex typing.

Gender, too, proved to be a strong influence on sex-role preferences within groups. Of 12 ANOVAs, there were five main effects and four interactions involving gender. Men selected more masculine discussion 
topics and the leader role in the group discussion. They eschewed the secretarial role and were less likely than women to prefer the position of ordinary group member. They also were less willing to change their role to oblige others' preferences. Despite these differences in preferences, there were no significant differences between men and women on the group behavioral data and the leadership ratings. Other researchers have found that men are more talkative and aggressive than women in groups under some conditions (Brooks, 1982; Kimbel et al., 1981; Piliavin \& Martin, 1978). In the present study, only the frequency of comments was recorded. While there were no gender differences on this measure, it is possible that had we recorded and analyzed other aspects of the group discussions such as vocal assertiveness and the task versus socioemotional nature of the comments, we might have uncovered evidence of traditional male-female roles. However, the failure to obtain a correspondence between sex role-related preferences and behavior within groups is worthy of note. It suggests that assumptions about how stereotyped and androgynous men and women act in social settings require empirical validation.

In this study, we explored the relation of sex-role attitudes and gender composition of social behavior preferences in groups composed of all stereotyped or all androgynous individuals. It is also important to begin examining how individuals whose sex-role attitudes are distinctive are assimilated into groups. Consider the typical experience of a token woman entering a male-dominated business or profession. It is likely that she possesses both the feminine/expressive attributes characteristic of women in general and the masculine/instrumental traits associated with achievement. While she may describe herself as androgynous, the group she joins is more likely than not composed of more traditional, sex-stereotyped men. An understanding of the psychological and social dynamics of such situations might ease the transition and improve working relationships. Clearly, the interaction of sex-role attitudes and behavior within groups of varying gender compositions is a fruitful area for further investigation.

\section{REFERENCES}

Andersen, M. Thinking about women: Sociological and feminist perspectives. New York: Macmillan, 1983.

Asch, S. Studies of independence and conformity. I. A minority of one against a unanimous majority. Psychological Monographs, 1956, 70(9), Whole No. 416.

Bem, S. L. The measurement of psychological androgyny. Journal of Consulting and Clinical Psychology, 1974, 42, 155-162.

Bem, S. L. Sex role adaptability: One consequence of psychological androgyny. Journal of Personality and Social Psychology, 1975, 31, 634-643. 
Bem, S. L., \& Lenney, E. Sex-typing and the avoidance of cross-sex behavior. Journal of Personality and Social Psychology, 1976, 33, 48-54.

Bem, S. L., Martyna, W., \& Watson, C. Sex typing and androgyny: Further explorations of the expressive domain. Journal of Personality and Social Psychology, 1976, 34, 1016-1023.

Brooks, V. R. Sex differences in student dominance behavior in female and male professors' classrooms. Sex Roles, 1982, 8, 683-690.

Burchardt, C. J., \& Serbin, L. A. Psychological androgyny and personality adjustment in college and psychiatric populations. Sex Roles, 1982, 8, 835-851.

Duval, S., \& Wicklund, R. A. A theory of objective self-awareness. New York: Academic Press, 1972.

Eagly, A. H. Sex differences in influenceability. Psychological Bulletin, 1978, 85, 86-116.

Gutek, B. A., \& Morasch, B. Sex-ratios, sex-role spillover, and sexual harassment of women at work. Journal of Social Issues, 1982, 38, 55-74.

Hammen, C. L., \& Peplau, L. A. Brief encounters: Impact of gender, sex-role attitudes, and partner's gender on interaction and cognition. Sex Roles, 1978, 4, 75-90.

Harrington, D. M., \& Andersen, S. M. Creativity, masculinity, femininity, and three models of psychological androgyny. Journal of Personality and Social Psychology, 1981, 41, 744-757.

Heilman, M. E. The impact of situational factors on personnel decisions concerning women: Varying the sex composition of the applicant pool. Organizational Behavior and $\mathrm{Hu}$ man Performance, 1980, 26, 386-395.

Helmreich, R. L., Spence, J. T., \& Wilhelm, J. A. A psychometric analysis of the Personal Attributes Questionnaire. Sex Roles, 1981, 7, 1097-1108.

Jones, W. H., Chernovetz, M. E., \& Hansson, R. O. The enigma of androgyny: Differential implications for males and females? Journal of Consulting and Clinical Psychology, 1978, 46, 298-313.

Kanter, R. M. Men and women of the corporation. New York: Basic Books, 1977. (a)

Kanter, R. M. Some effects of proportions on group life: Skewed sex ratios and responses to token women. American Journal of Sociology, 1977, 82, 965-990. (b)

Kimble, C. E., Yoshikawa, J. C., \& Zehr, H. D. Vocal and verbal assertiveness in same-sex and mixed-sex groups. Journal of Personality and Social Psychology, 1981, 40, 1047-1054.

McGuire, W. J., \& Padawer-Singer, A. Trait salience in the spontaneous self-concept. Journal of Personality and Social Psychology, 1976, 33, 743-754.

Orlofsky, J. L. Relationship between sex role attitudes and personality traits and the Sex Role Behavior Scale-1: A new measure of masculine and feminine role behaviors and interests. Journal of Personality and Social Psychology, 1981, 40, 927-940.

Piliavin, J. A., \& Martin, R. R. The effects of the sex composition of groups on style of social interaction. Sex Roles, 1978, 4, 281-296.

Ruble, D. N., \& Higgins, E. T. Effects of group sex composition on self-presentation and sextyping. Journal of Social Issues, 1976, 32, 125-132.

Spence, J. T., \& Helmreich, R. L. Masculinity and femininity: Their psychological dimensions, correlates and antecedents. Austin: University of Texas Press, 1978.

Spence, J. T., Helmreich, R. L., \& Stapp, J. The Personal Attributes Questionnaire: A measure of sex-role stereotypes and masculinity-femininity. JSAS Catalog of Selected Documents in Psychology, 1974, 4, 43 (Ms. No. 617).

Taylor, M. C., \& Hall, J. A. Psychological androgyny: Theories, methods, and conclusions. Psychological Bulletin, 1982, 92, 347-366.

Taylor, S. E., Fiske, S. T., Etcoff, N. L., \& Ruderman, A. J. Categorical and contextual bases of person memory and stereotyping. Journal of Personality and Social Psychology, 1978, 36, 778-793. 
Copyright of Sex Roles is the property of Springer Science \& Business Media B.V. and its content may not be copied or emailed to multiple sites or posted to a listserv without the copyright holder's express written permission. However, users may print, download, or email articles for individual use. 